\title{
Oesophageal rhabdomyoma
}

\author{
F Roberts, A J B Kirk, I A R More, J Butler, R P Reid
}

\begin{abstract}
Extracardiac rhabdomyomas are rare benign tumours showing striated muscle differentiation. Seventy percent of these lesions occur in the head and neck region. The most common sites for these lesions are the larynx, pharynx, and the floor of the mouth. There has been only one previous report of a rhabdomyoma of the oesophagus; two further cases are described.

(F Clin Pathol 2000;53:554-557)
\end{abstract}

Keywords: rhabdomyoma; oesophagus

Extracardiac rhabdomyoma is a benign tumour showing striated muscle differentiation. It is distinct from cardiac rhabdomyoma, which is considered to be a hamartomatous lesion often associated with tuberous sclerosis. ${ }^{1}$ Extracardiac rhabdomyomas are rare tumours. Three subtypes are generally recognised: fetal, genital, and adult rhabdomyoma. ${ }^{2}$ Fetal rhabdomyoma occurs primarily in the subcutaneous tissues of the head and neck of male infants usually less than 3 years of age. Genital rhabdomyomas are slow growing lesions in the vagina or vulva of young or middle aged women. Adult rhabdomyomas occur at a mean age of approximately 50 years although there is a wide age range. ${ }^{2}$ They have a predilection for the head and neck region. Some authors also include rhabdomyomatous mesenchymal hamartoma as a fourth subtype of rhabdomyoma. ${ }^{3}$ This is an unusual lesion that occurs principally on the face and neck of infants and young children. It consists of striated muscle bundles interspersed with islands of adipose tissue, fibrous tissue, and occasionally proliferated nerves. ${ }^{3}$

There has been only one previous report of a rhabdomyoma of the oesophagus, which was of adult subtype. ${ }^{4}$ This lesion occurred in the upper thoracic oesophagus of an 8 year old boy. Histological examination revealed a well encapsulated tumour composed of randomly orientated muscle fibres with numerous cross striations. We present two further cases of rhabdomyoma of the oesophagus. The clinical, histological, and electron microscopic features of this rare lesion are described and the differential diagnosis discussed.

Department of

Cardiothoracic

Surgery, Western

Infirmary

A J Kirk

J Butler

Correspondence to: Dr F Roberts email: f.roberts@spr.co.uk

Accepted for publication 4 November 1999 filling defect in the oesophagus (fig 1). Computed tomography (CT) scanning suggested that the oesophagus was being compressed by an extrinsic lesion. Subsequently, at surgery, a firm

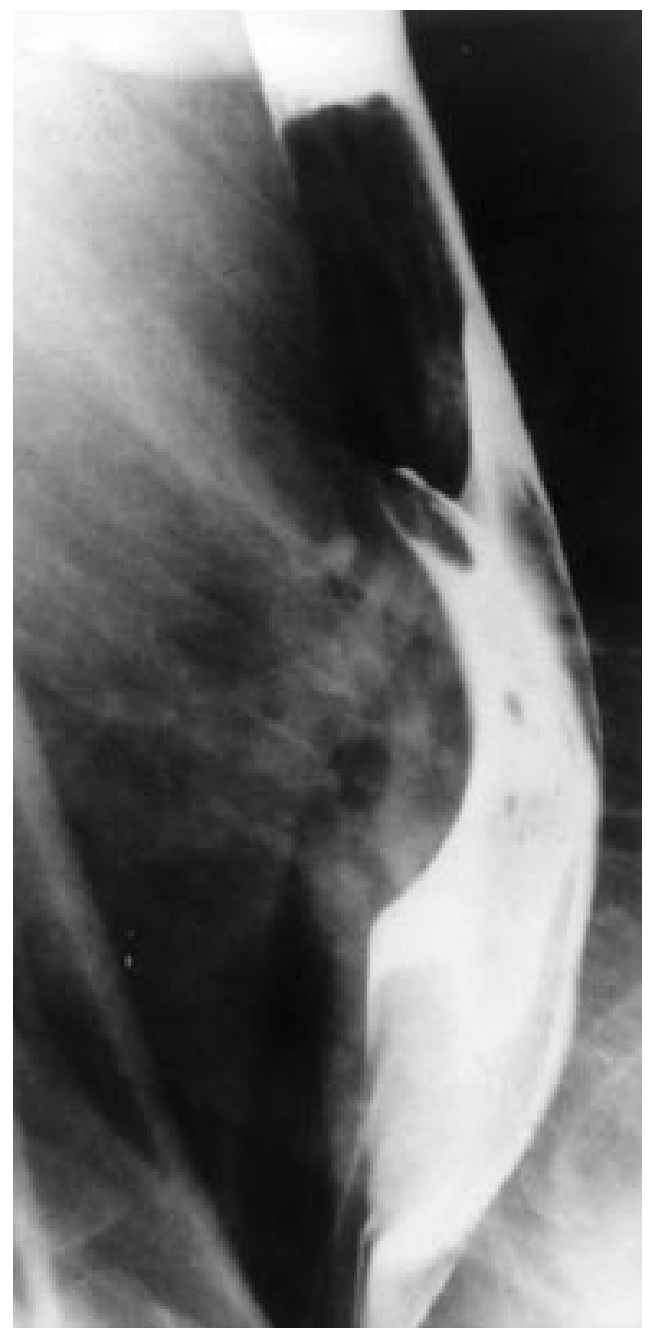

Figure 1 Barium swallow showing a well circumscribed filling defect in the mid-oesophagus.

lobulated lesion was identified within the wall of the middle third of the oesophagus. A longitudinal myotomy was made over the lesion, which was then excised. The postoperative period was uneventful and the patient was discharged home. Six weeks later she had made a full recovery and her symptoms of dysphagia had completely resolved.

\section{Pathological findings}

The surgical specimen comprised a partially encapsulated firm white mass measuring $90 \times 35 \times 5 \mathrm{~mm}$. The cut surface displayed a whorled pattern. Histological examination of the lesion showed a tumour composed of interlacing fascicles of spindle shaped cells. Interspersed between the spindle cells there were large ovoid cells with copious eosinophilic cytoplasm (fig 2A). Phosphotungstic acid haematoxylin showed clear cross striations in many 

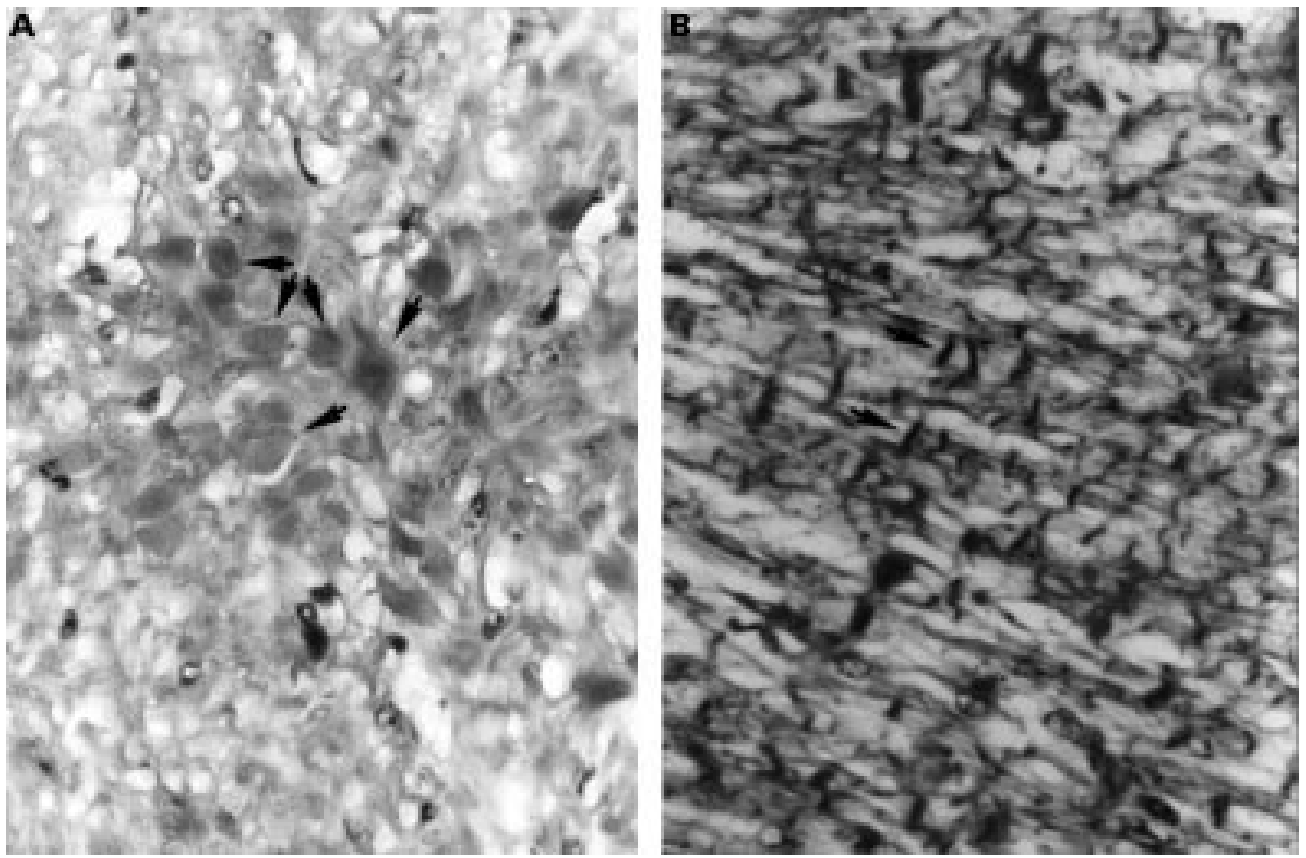

Figure 2 (A) Some areas contain large ovoid cells with copious eosinophilic cytoplasm (arrows) (haematoxylin and eosin). (B) Cross striations (arrows) within the spindle shaped cells (phosphotungstic acid haematoxylin).

of the spindle shaped cells. Immunohistochemical staining for muscle specific actin (Lipshaw, Pittsburgh, Pennsylvania, USA) and desmin (Lipshaw) was strongly positive. Cytogenetic analysis of the tumour revealed a normal female karyotype. Electron microscopy performed on glutaraldehyde fixed material showed spindle shaped cells containing alternating thick (myosin) and thin (actin) myofilaments (fig 3). There was focal condensation of these thick and thin filaments to form rudimentary $\mathrm{Z}$ bands (fig 3). Consistent with myocyte differentiation the tumour cells also contained numerous mitochondria and clusters of glycogen particles.

CASE 2

A 30 year old man presented with epigastric pain and symptoms of reflux oesophagitis. Endoscopy showed a submucosal mass. This was confirmed on barium meal, which also demonstrated a sliding hiatus hernia. Biopsy of this mass suggested a leiomyoma of the oesophagus. At surgery the lesion was identified in the distal oesophagus. This could not be reached with a rigid oesophagoscope and a left lateral thoracotomy was therefore performed. The pleura and muscle were incised and the tumour was freed from the overlying mucosa. The postoperative period was uneventful and the patient was discharged home after five days. Six weeks later he had made a full recovery and was discharged from follow up.

\section{Pathological findings}

The surgical specimen consisted of an irregularly shaped firm white tumour received in two pieces, measuring $55 \times 30 \times 20 \mathrm{~mm}$ and $20 \times 20 \times 6 \mathrm{~mm}$, respectively. Histological examination showed a lobulated tumour composed of spindle shaped cells. Similar to the first case, there were numerous groups of large

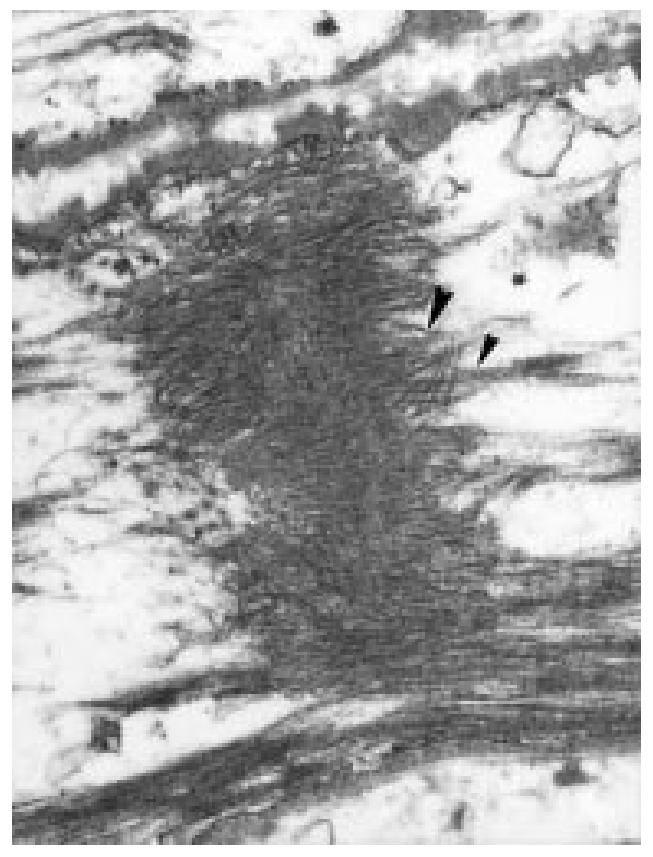

Figure 3 Electron microscopy shows focal condensation of thick (large arrowhead) and thin (small arrowhead) filaments to form rudimentary $Z$ bands.

ovoid cells with eosinophilic cytoplasm interspersed between the spindle cells. Phosphotungstic acid haematoxylin showed clear cross striations in many of the spindle shaped cells (fig 2B). Immunohistochemical staining for muscle specific actin and desmin was again strongly positive. Similar to case 1, electron microscopy performed on formalin fixed material showed spindle shaped cells containing alternating thick (myosin) and thin (actin) myofilaments. There was focal condensation of these thick and thin filaments to form rudimentary $\mathrm{Z}$ bands. The tumour cells also 
contained numerous mitochondria and clusters of glycogen particles.

\section{Discussion}

Extracardiac rhabdomyomas are extremely rare tumours comprising less than $2 \%$ of all neoplasms showing striated muscle differentiation. The three commonly recognised subtypes, adult, fetal, and genital, are clinically and morphologically distinct. The most common sites for the adult subtype are the larynx, pharynx, and the floor of the mouth. ${ }^{2}$ Unusual sites include the orbit, ${ }^{5}$ stomach, ${ }^{6}$ mediastinum, ${ }^{7}$ prostate, ${ }^{8}$ and heart. ${ }^{9}$ They usually present as a slow growing, solitary mass. As in the two cases described, clinical symptoms are often related to obstruction of the aerodigestive tract. ${ }^{2}$ Uncommonly these tumours may present with multiple nodules in the same location. ${ }^{10}$

The characteristic histological features of adult rhabdomyoma are sheets of large ovoid or polygonal cells with eosinophilic cytoplasm. ${ }^{2}$ The cytoplasm may be finely granular or vacuolated owing to the presence of glycogen. Cytoplasmic cross striations are usually difficult to identify on routine haematoxylin and eosin sections, but can be identified in some cases with a phosphotungstic acid haematoxylin. Most cells in adult rhabdomyoma can be immunostained with antibodies to muscle specific actin, desmin, and myoglobin. ${ }^{11}$ Fetal rhabdomyomas originate in the subcutaneous tissues of the head and neck of male infants. They are composed of a mixture of undifferentiated spindle shaped cells with an indistinct cytoplasm and myoblasts at different stages of differentiation. ${ }^{2}$ Genital rhabdomyoma is a submucosal lesion occurring in the vagina or vulva composed of elongated strap like cells usually with prominent cross striations. ${ }^{2}$

Electron microscopy of these lesions shows variable numbers of rudimentary myofibrils in the cytoplasm of virtually all of the cells. ${ }^{11}{ }^{12}$ These myofibrils are composed of alternating thick (15 nm myosin) and thin (6 $\mathrm{nm}$ actin) myofilaments. Focal condensation of myofibrils forms $\mathrm{Z}$ bands. The cytoplasm of the myocytes contains numerous mitochondria. These might show a range of abnormalities, the most common of which is the presence of parallel arrays of cristae containing electron dense material. ${ }^{12}$ Mitochondria were numerous within the tumour cells of the two cases described; however, poor fixation precluded assessment of mitochondrial substructure. $\mathrm{Z}$ bands and structurally abnormal mitochondria are less prominent in the fetal subtype of rhabdomyoma. ${ }^{13}$ Variable numbers of glycogen particles are found within the cytoplasm in most of the tumour cells. ${ }^{12}$

The two cases described in this case report fit best with an adult type rhabdomyoma with large ovoid cells. In some areas, the lesions were composed of spindle shaped cells but these were much less cellular than a classic fetal rhabdomyoma. Furthermore, electron microscopy demonstrated numerous rudimentary $\mathrm{Z}$ bands, which are usually inconspicuous in a fetal rhabdomyoma.
The differential diagnoses for oesophageal rhabdomyoma include leiomyoma and granular cell tumour. The initial biopsy in case 2 suggested a leiomyoma of the oesophagus and this is therefore an important differential diagnosis. Leiomyomas are the most common benign tumours of the oesophagus. ${ }^{14}$ They usually arise within the muscle layers of the distal third of the oesophagus and are easy to "shell out" at surgery. In the two cases described, both surgeons commented that the lesion was difficult to shell out and appeared to be incorporated into the surrounding tissues. Microscopically, leiomyomas are composed of interlacing fascicles of spindle shaped cells that stain positively for desmin and smooth muscle actin. The large ovoid cells present in adult rhabdomyoma are absent. Electron microscopy shows numerous cytoplasmic filaments, pinocytotic vesicles, and a thick basal lamina, ${ }^{15}$ but there are no $\mathrm{Z}$ bands or alternating thick and thin filaments.

Striated muscle differentiation has been observed occasionally in leiomyomas-for example, within the uterus. ${ }^{16}$ These authors describe a lesion composed predominantly of spindle shaped cells with blunt ended nuclei. In some areas there were ribbon like and polygonal cells with abundant eosinophilic cytoplasm. These cells stained positively for muscle specific actin whereas the spindle cells were negative. In the two cases described herein, the nuclei of the spindle cells were not characteristic of a leiomyoma. Furthermore, both the spindle and ovoid cells stained positively for muscle specific actin, and rudimentary $Z$ bands were identified within most tumour cells on electron microscopy.

Granular cell tumours of the oesophagus are usually situated in the submucosa and are associated with pseudoepitheliomatous hyperplasia of the overlying mucosa. ${ }^{17}$ The two oesophageal rhabdomyomas described in our report were situated within the muscularis propria of the oesophagus. Furthermore, granular cell tumours stain positively for S-100 protein and are negative for desmin. ${ }^{17}$ In our two cases, the large ovoid cells were negative for S-100 protein and positive for desmin.

The cell of origin of these tumours is uncertain, but most probably they arise from primitive mesenchymal stem cells that undergo striated muscle differentiation, and not from differentiated striated muscle tissue. This is analogous to rhabdomyosarcoma, which can arise in areas in which there is no striated muscle, such as the bladder and bile duct. ${ }^{18}$ The recommended treatment for adult rhabdomyomas is complete excision. Removal of the lesion resulted in complete resolution of symptoms in the two cases described. Recurrence is rare and is thought to be associated with incomplete resection. $^{2}$

1 Burke AP, Virmani R. Cardiac rhabdomyoma. Mod Pathol $1991 ; 4: 70-4$.

2 Willis J, Abdul-Karim F, di Sant'Agnese PA. Extracardiac rhabdomyomas. Semin Diagn Pathol 1994;11:15-25.

3 Enzinger FM, Weiss SW. Rhabdomyoma. In: Enzinger FM, Weiss SW, eds. Soft tissue tumours, 3rd ed. St Louis: Mosby,
1995:523-37. 
4 Pai GK, Pai PK, Kamath SM. Adult rhabdomyoma of the esophagus. F Pediatr Surg 1987;22:991-2.

Knom of the orbit. Am f Ophthalmol 1975;80:1011-18.

6 Tuazon R. Rhabdomyoma of the stomach. Report of a case. Am f Clin Pathol 1968;52:37-41.

7 Miller R, Kurtz SM, Powers JM. Mediastinal rhabdomyoma. Cancer 1978;42:1983-8.

8 Morra MN, Manson AL, Gavrell GJ. Rhabdomyoma of prostate. Urology 1992;29:271-3.

9 Yu GH, Kussmaul WG, diSesa VJ, et al. Adult intracardiac rhabdomyoma resembling the extracardiac variant. Hum Pathol 1993;24:448-51.

10 Kapadia SB, Meis JM, Frisman DM, et al. Adult rhabdomyoma of the head and neck. A clinicopathologic and immunophenotypic study. Hum Pathol 1993;24:60817 .

11 Helliwell TR, Sisson MCJ, Stoney PJ, et al. Immunohistochemistry and electron microscopy of head and neck rhabdomyoma. 7 Clin Pathol 1988;41:1058-63.
12 Warner TFCS, Goell W, Sundharades M, et al. Adult rhabdomyoma. Ultrastructure and immunocytochemistry. Arch domyoma. Ultrastructure and imm

13 Konrad EA, Meister P, Hubner G. Extracardiac rhabdomyoma. Report of different types with light microscopic and ultrastructural studies. Cancer 1982;49:898-907.

14 Solomon MP, Rosenblum H, Rosato FE. Leiomyoma of the esophagus. Ann Surg 1984;199:246-8.

15 Mackay B, Ro J, Floyd C, et al. Ultrastructural observations in smooth muscle tumors. Ultrastruct Pathol 1987;11:593607.

16 Fornelli A, Pasquinelli G, Eusebi V. Leiomyoma of the uterus showing skeletal muscle differentiation: a case report. Hum Pathol 1999;30:356-9.

17 de S Coutinho DS, Soga J, Yoshikawa T, et al. Granular cell tumors of the esophagus. A report of two cases and review of the literature. Am $\mathcal{F}$ Gastroenterol 1985;80:758-62.

18 Enzinger FM, Weiss SW. Rhabdomyosarcoma. In: Enzinger FM, Weiss SW, eds. Soft tissue tumours, 3rd ed. St Louis: Mosby, 1995:539-77.

\section{Fournal of Clinical Pathology - http://www.jclinpath.com}

Visitors to the world wide web can now access the fournal of Clinical Pathology either through the BMJ Publishing Group's home page (http://www.bmjpg.com) or directly by using its individual URL (http://www.jclinpath.com). There they will find the following:

- Current contents list for the journal

- Contents lists of previous issues

- Members of the editorial board

- Information for subscribers

- Instructions for authors

- Details of reprint services

- Instructions for use of Pathology Interactive.

A hotlink gives access to:

- BMJ Publishing Group home page

- British Medical Association web site

- Online books catalogue

- BMJ Publishing Group books.

The web site is at a preliminary stage and there are plans to develop it into a more sophisticated site. Suggestions from visitors about features they would like to see are welcomed. They can be left via the opening page of the BMJ Publishing Group site or, alternatively, via the journal page, through "about this site". 